\title{
Development of the Home Pregnancy Test
}

\author{
JUDITH L. VAITUKAITIS, MD
}

Director, National Center for Research Resources, National Institutes of Health, Bethesda, Maryland 20892, USA

\begin{abstract}
The home pregnancy testworks by measuring human chorionic gonadotropin (hCG) hormone in urine. This hormone was initially studied in NICHD intramural laboratories as a reliable marker of certain tumors. Refinement of the assay for hCG detection to enhance specificity enabled its ready application to pregnancy detection.
\end{abstract}

KEYWORDS: home pregnancy test; reproductive endocrinology; human chorionic gonadotropin; hCG

Am I pregnant? The answer to this age-old question once demanded a combination of guesswork, intuition, and time. In 1978, however, the long wait to know for sure became a thing of the past. Trumpeted by advertisements as "a private little revolution," the first home pregnancy tests started appearing on drug store shelves that year.

The pregnancy test works by identifying the presence of the "pregnancy hormone," human chorionic gonadotropin (hCG), in urine. Research that led to a sensitive, accurate test for hCG was done in the Reproductive Research Branch of the National Institute of Child Health and Human Development at $\mathrm{NIH}$. For young researchers interested in reproductive endocrinology in the late 1960s, the NICHD was an ideal location. Glenn Braunstein and I were both medical residents at different Boston hospitals in 1969 interested in reproductive endocrinology. From our respective mentors, we each heard the same message: go to Bethesda and talk to physician scientists Mort Lipsett and Griff Ross. The NIH was one of the few places in the country where one could do reproductive endocrinology; it was really a new field.

Human chorionic gonadotropin (hCG) was a fascinating hormone to study in 1970, partly because not much was known about its behavior or makeup. We did know that the human body secretes hCG only during pregnancy or during certain kinds of cancers. If we could find a way to precisely measure

Address for correspondence: Judith L. Vaitukaitis, MD, Director, National for Research Resources, National Institutes of Health, Building 31, Room 3B11, 9000 Rockville Pike, Bethesda, MD 20892-2128. Voice: 301-496-5793; fax; 301-402-0006.

judyv@ncrr.nih.gov

Ann. N.Y. Acad. Sci. 1038: 220-222 (2004). (c) 2004 New York Academy of Sciences.

doi: 10.1196/annals.1315.030 
this hormone, we would have a reliable tumor marker, as well as a way to identify problems with a pregnancy. The National Cancer Institute's Dr. Roy Hertz was studying a cancer called choriocarcinoma at the time. In this disease, patients exhibited tumors that secreted hCG and if blood samples could be tested reliably for the presence of hCG, tumor response during treatment could be tracked.

We knew that the existing bioassay was very crude and insensitive, though it was better than anything else available at that time. We needed another way of measuring hCG in the presence of a finite amount of luteinizing hormone (LH). While we were doing this, we had no idea of the impact on early pregnancy detection. I was working at separating the subunits of hCG and determining their biological function and characteristics. In 1970 and 1971 we generated an antibody that was specific to the beta-subunit of hCG and that could therefore be used in a radioimmunoassay and would not cross-react with other hormones. The first rabbit to produce the antibody was called "SB6" and became the baseline for future experiments.

It was critical for Dr. John Robbins of NICHD to be involved in this, because John had the immunology background. We tried two doses of immunogen to make the antibody, 10 and 50 micrograms, and the animal that had the first dose of 50 micrograms of immunogen was labeled SB6, since it was the sixth rabbit. There were five rabbits immunized with 10 micrograms, and we were told they would never make antibody at 10 . However, we went down as low as 2 micrograms and documented a response at that dose. The first animal immunized with 50 micrograms, SB6, yielded the classic antiserum that had the best relative specificity and was used for years. In 1972, we were ready to publish our paper on hCG research, in which we described the methodology for using antibodies to the beta subunit of hCG in a radioimmunoassay to identify and measure hCG in the presence of LH. This became the basis for the home pregnancy test which is so widely used today.

The following website contains a history of research related to the home pregnancy test:

$<$ http://www.history.nih.gov/exhibits/thinblueline/>.

\section{BIBLIOGRAPHY}

Braunstein, G.D., J.L. VAitukaitis \& G.T. Ross. 1972. The in vivo behavior of human chorionic gonadotropin after dissociation into subunits. Endocrinology 91(4):1030-1036.

Vaitukaitis, J.L., G.D. Braunstein \& G.T. Ross. 1972. A radioimmunoassay which specifically measures human chorionic gonadotropin in the presence of human luteinizing hormone. Am. J. Obstet. Gynecol. 113(6):751-758.

RAYFORD, P.L., J.L. VAITUKAITIS, G.T. Ross, et al. 1972. Use of specific antisera to characterize biologic activity of hCG-beta subunit preparations. Endocrinology 91(1):144-146. 
Vaitukaitis, J.L., G.T. Ross, J.G. Pierce, et al. 1973. Generation of specific antisera with the hormone-specific beta-subunit of hTSH or hFSH. J. Clin. Endocrinol. Metab. 37(5): 653-659.

VAITUKAITIS, J.L. 1973. Immunologic and physical characterization of human chorionic gonadotropin (hCG) secreted by tumors. J. Clin. Endocrinol. Metab. 37(4): 505-514.

Goldenberg, R.L., E.O. Reiter, J.L. Vaitukaitis \& G.T. Ross. 1973. Hormonal factors influencing ovarian uptake of human chorionic gonadotropin. Endocrinology 92(5): 1565-1567.

Hodgen, G.D., W.E. Nixon, J.L. Vaitukaitis, et al. 1973. Neutralization of primate chorionic gonadotropin activities by antisera against the subunits of human chorionic gonadotropin in radioimmunoassay and bioassay. Endocrinology 92(3): 705-709.

Braunstein, G.D., J.L. Vaitukaitis, P.P. Carbone \& G.T. Ross. 1973. Ectopic production of human chorionic gonadotrophin by neoplasms. Ann. Intern. Med. 78(1): 39-45.

Vaitukaitis, J.L. \& G.T. Ross. 1973. Recent advances in evaluation of gonadotropic hormones. Annu. Rev. Med. 24: 295-302.

Hodgen, G.D., W.W. Tullner, J.L. Vaitukaitis, et al. 1974. Specific radioimmunoassay of chorionic gonadotropin during implantation in rhesus monkeys. J. Clin. Endocrinol. Metab. 39(3): 457-464.

VAitukAitis, J.L. 1974. Human chorionic gonadotropin as a tumor marker. Ann. Clin. Lab. Sci. 4(4): 276-280.

Morgan, F.J., R.E. Canfield, J.L. Vaitukaitis \& G.T. Ross. 1974. Properties of the subunits of human chorionic gonadotropin. Endocrinology 94(6): 1601-1606.

VAITUKaitis, J.L. 1974. Changing placental concentrations of human chorionic gonadotropin and its subunits during gestation. J. Clin. Endocrinol. Metab. 38(5): 755-760.

VAITUKAITIS, J.L. 1975. Editorial: When is a tumor marker not a tumor marker? N. Engl. J. Med. 293(26): 1370-1371.

Catt, K.J., M.L. Dufau \& J.L. Vaitukaitis. 1975. Appearance of hCG in pregnancy plasma following the initiation of implantation of the blastocyst. J. Clin. Endocrinol. Metab. 40: 537-540.

Vigersky, R.A., D.L. Loriaux, A.E. Andersen, et al. 1976. Delayed pituitary hormone response to LRF and TRF in patients with anorexia nervosa and with secondary amenorrhea associated with simple weight loss. J. Clin. Endocrinol. Metab. 43(4): 893-900.

VAitukAitis, J.L.\& E.R EBersole. 1976. Evidence for altered synthesis of human chorionic gonadotropin in gestational trophoblastic tumors. J. Clin. Endocrinol. Metab. 42(6):1048-1055.

Vaitukaitis, J.L., G.T. Ross, G.D. Braunstein \& P.L. Rayford. 1976. Gonadotropins and their subunits: basic and clinical studies. Recent Prog. Horm. Res. 32: 289-331.

Albertson, B.D. \& J.L. Vaitukaitis. 1977. Role of cyclic nucleotides in modulating ovarian hCG action. Endocr. Res. Commun. 4(6): 367-378. 